\title{
Los desafíos de la mirada La función de la crítica en la era del cine
}

Christian León Mantilla

Entre las restricciones a causa de la pandemia está la limitación para asistir a las salas de cine. A la crisis del sector, se suma este nuevo escenario. Cristian León, coordinador de la Maestría en Comunicación Estratégica de la UASB-E y autor de varios libros sobre cultura visual, reflexiona en este contexto y señala la importancia de los desafíos que plantea la crítica cinematográfica y las transformaciones de enfoques y tecnologías que resultan imprescindibles.

$\mathbf{E}$ scribo estas líneas en un escenario sin precedentes en la historia humana. La pandemia originada por el COVID-19 y la consecuente crisis sanitaria global plantean un horizonte vital marcado por el aislamiento domiciliario y el distanciamiento social. Esta circunstancia - en otros tiempos inverosímil- ha generado la suspensión de actividades de todas las industrias culturales y espectáculos públicos en la mayoría de países del planeta. Con producciones detenidas, estrenos suspendidos, festivales cancelados y salas cerradas, el mundo del cine afronta una de las mayores crisis de su historia.

Sin lugar a dudas, la pandemia aceleró una serie de transformaciones que estaban sucediendo lentamente en la producción, distribución, exhibición y consumo de películas, a tal punto que aquella experiencia que denominábamos cine se encuentra en vías de disolución en el universo ampliado de las formas postcinematográficas. El consumo y la producción audiovisual definitivamente han entrado en la cultura transmedia, acoplándose a la producción digital, la multiplicidad de pantallas, la portabilidad de la imagen y el consumo bajo demanda. El acto de ir al cine - como un ritual social de confrontación cinéfila frente a la gran pantalla - es cada vez más un evento minoritario.

\section{6}

El consumo y la

producción audiovisual

definitivamente han

entrado en la cultura transmedia, acoplándose a la producción digital, la multiplicidad de pantallas, la portabilidad de la imagen y el consumo bajo demanda. 


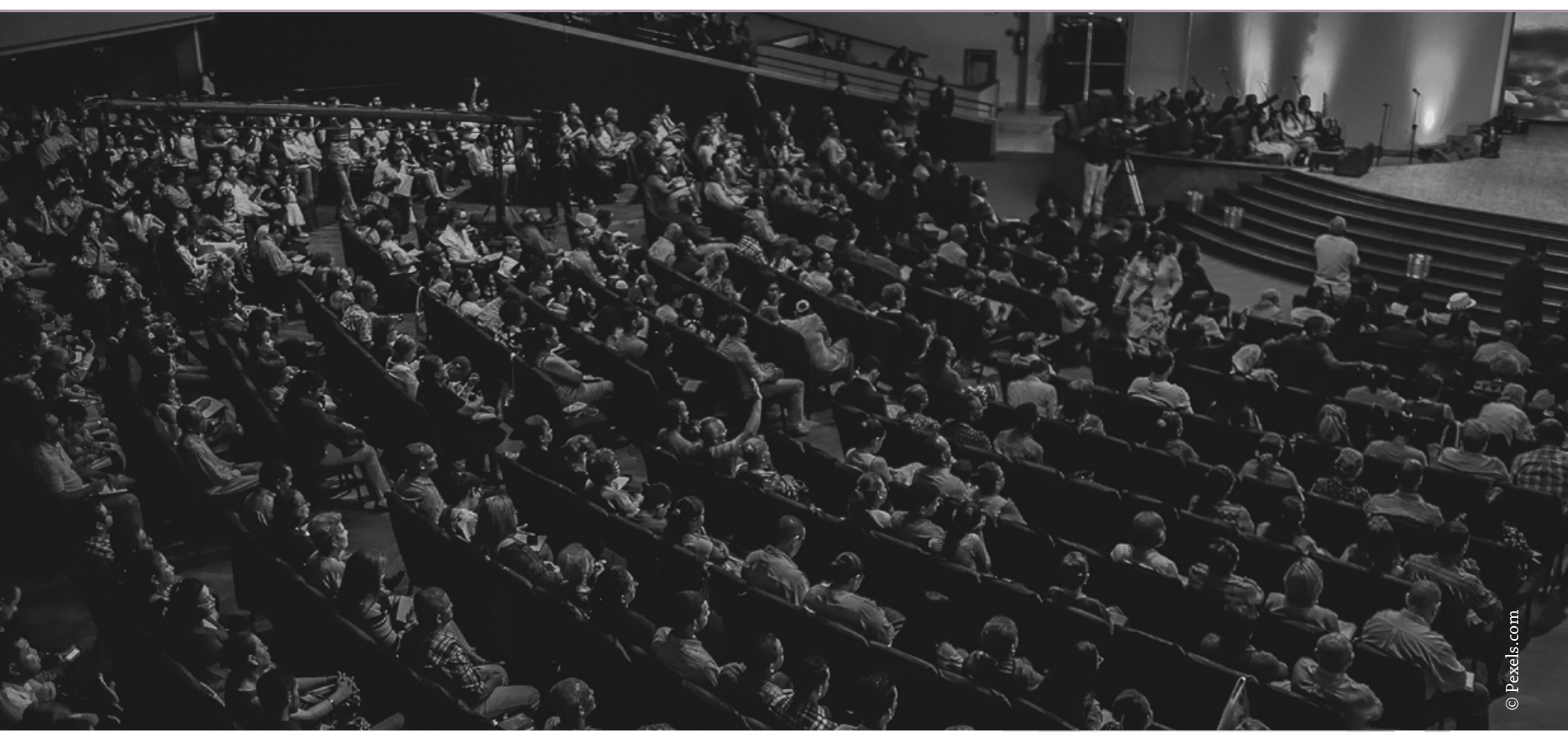

La pandemia marca el cierre de un ciclo, el fin de la experiencia cinematográfica como la hemos conocido hasta ahora. La producción, el lenguaje, la tecnología, el canon, los valores, los espectadores, los rituales del consumo que primaron gloriosamente durante el siglo XX, hoy pierden su centralidad. En el desconcertante futuro que se avecina, sin lugar a dudas, seguirán existiendo películas, pero ya no aquella institución social que se sostuvo en la producción industrial, la tecnología de impresión fotoquímica, la proyección óptica, la puesta en escena, el montaje, el ritual de la sala oscura y la cinefilia. En esta compleja transición postcinematográfica, acelerada por el coronavirus, me planteo la pregunta sobre el lugar de la crítica de cine, su función social y su futuro.

La crítica es una de las instituciones que sostienen el mundo del cine. Es la práctica de la interpretación para la construcción social del sentido de las películas, la apertura del debate público y la legitimización de la experiencia cinematográfica. Es un oficio que revela la disputa por el sentido que tienen distintos actores en el mundo social. Por esta razón, la crítica hace evidente que el sentido de un filme es una construcción abierta y plural necesaria para la sociedad democrática y libre.

A lo largo del desarrollo de la historia del cine, la crítica - ejercida en diarios, revistas especializadas y medios académicos - fue una especie de batallón de avanzada que abrió el campo para el debate de nuevos lenguajes, tendencias

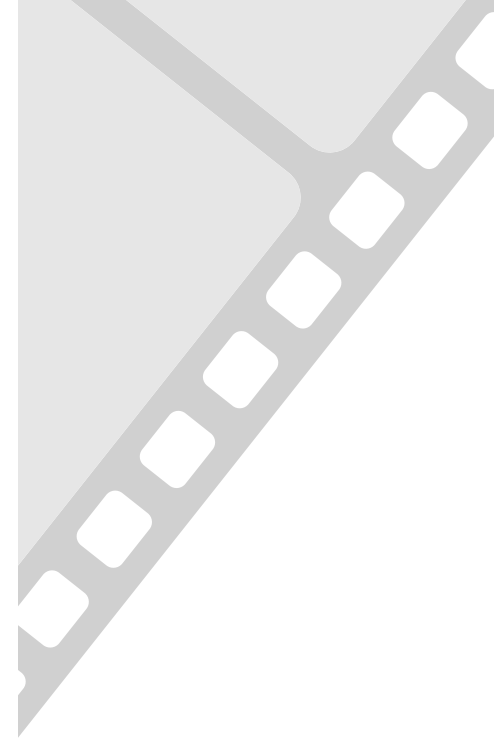

\section{6}

\section{La crítica hace}

evidente que el sentido

de un filme es una

construcción abierta

y plural necesaria

para la sociedad

democrática y libre. 


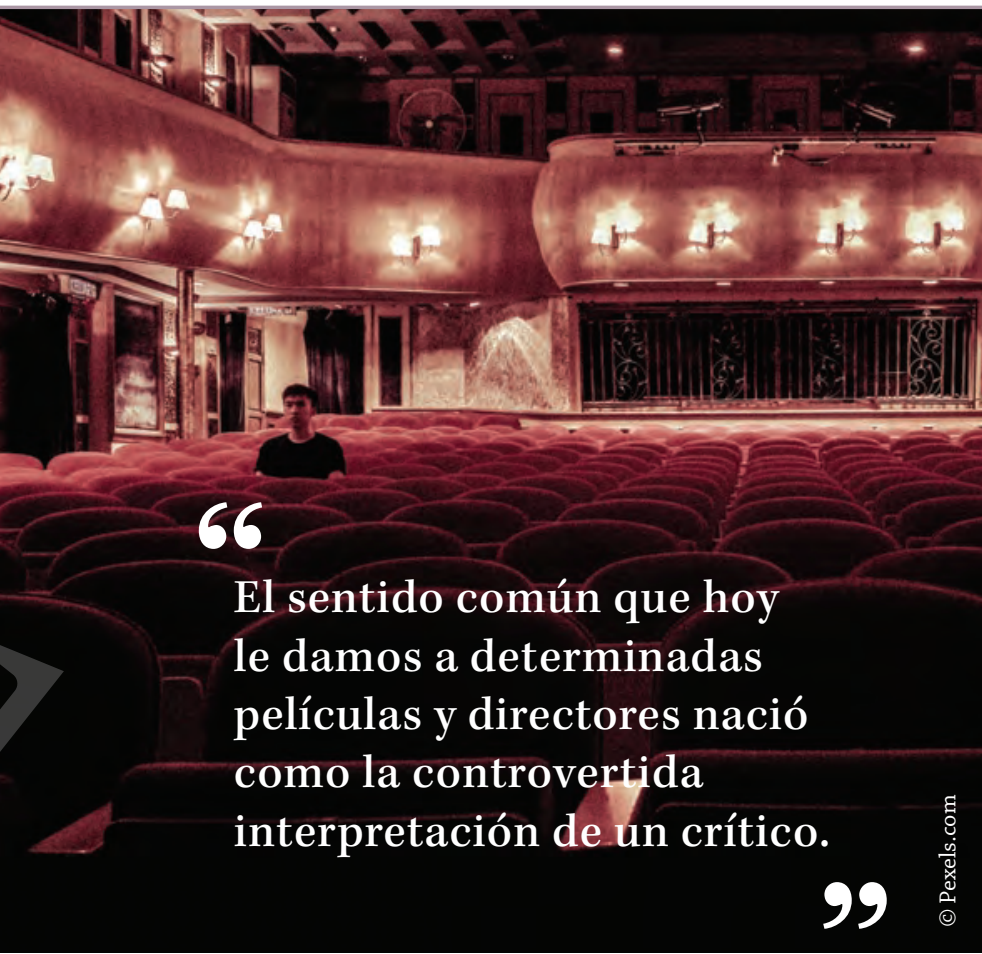

y sentidos. La crítica permitió que gran parte de los nuevos desarrollos tecnológicos, estéticos y conceptuales del cine se discutieran en la sociedad, fueran aceptados y tuvieran legibilidad. Es por esta razón que hoy más que nunca requerimos de la crítica. En un momento de radicales transformaciones de las prácticas audiovisuales, necesitamos nombrarlas, valorarlas, dotarlas de sentido. He ahí una de las funciones del crítico en la época del postcine, en tiempos de pandemia.

Recurro aquí a Roland Barthes, quien nos enseñó que la crítica es una práctica creadora que se-

para, distingue y desdobla los sentidos a través de un trabajo con la escritura. Es por esta razón que lejos de juzgar o explicar una obra, construye su sentido, crea un significado que no existía y lo legitima socialmente a través de un punto de vista y una escritura que se abre al debate público. El sentido común que hoy le damos a determinadas películas y directores nació como la controvertida interpretación de un crítico. Pienso en la lectura de André Bazin sobre el neorrealismo, la interpretación de François Truffaut sobre Alfred Hitchcock o la de Rudy Rich sobre el New Queer Cinema.
Ensayo

Esta tarea de creación del sentido está atada a la figura del individuo y la libertad de pensamiento, que surge en el mundo occidental como resistencia a la autoridad de la Iglesia, las instituciones tradicionales y las verdades establecidas. En este contexto, se entiende la audaz tesis de Michel Foucault, quien sostiene que la actitud crítica se basa en un deseo de «no querer ser gobernado".

Estas ideas del filósofo revelan no solo el rol político, sino también ético de la crítica, ya que detrás del discurso crítico existe un sujeto que enuncia y se afirma a sí mismo a través de la escritura. Un sujeto que se planta frente a las instituciones y el poder para interrogarlas e interpelarlas desde sí mismo. De ahí que el discurso de la crítica descanse en la construcción de una voz, una mirada y un personae que interpela al mundo desde su subjetividad: un nombre propio que opina, arriesga e interpreta desde sus experiencias, gustos, concepciones e ideología. Por esta razón, considero que hacer crítica es la virtud de construirse a uno mismo, de forjarse un nombre, una voz y un punto de vista. Aquí radica la diferencia entre la crítica y el ensayo científico, que se escuda tras la coartada de la objetividad.

En un mundo cada vez más homogenizado por las industrias culturales y, paradójicamente, sometido a la dictadura del yo - por el giro subjetivo, la autocomunicación y las redes sociales-, la crítica sostiene heroicamente el prurito de construir un rostro, una voz, una firma capaz de interpelar al mundo y sus creaciones desde un punto de vista personal y una distancia interpretativa. He aquí otro argumento para afirmar la necesidad de la crítica en un mundo en crisis urgido de intérpretes, como el que vivimos en la actualidad.

Por lo dicho, parecería que la crítica está asociada con el universo interior del intérprete. Nada más lejano de su práctica. La crítica es una apuesta interpretativa y personal que está construida institucionalmente. Sus operaciones 
están moduladas por el lenguaje, las convenciones discursivas, los saberes técnicos, estéticos, filosóficos, la historia de la interpretación, los medios y las instituciones a través de los cuales se expresa. En el campo específico del cine, nos referimos a la redacción, al género y al estilo de crítica cinematográfica; al dominio de la estética del cine; a las competencias analíticas del lenguaje audiovisual; al conocimiento de la teoría e historia del cine; al pensamiento de la imagen basado en distintas disciplinas; a la legitimidad del medio en el cual escribe el crítico; y a la autoridad social que legitima sus enunciaciones.

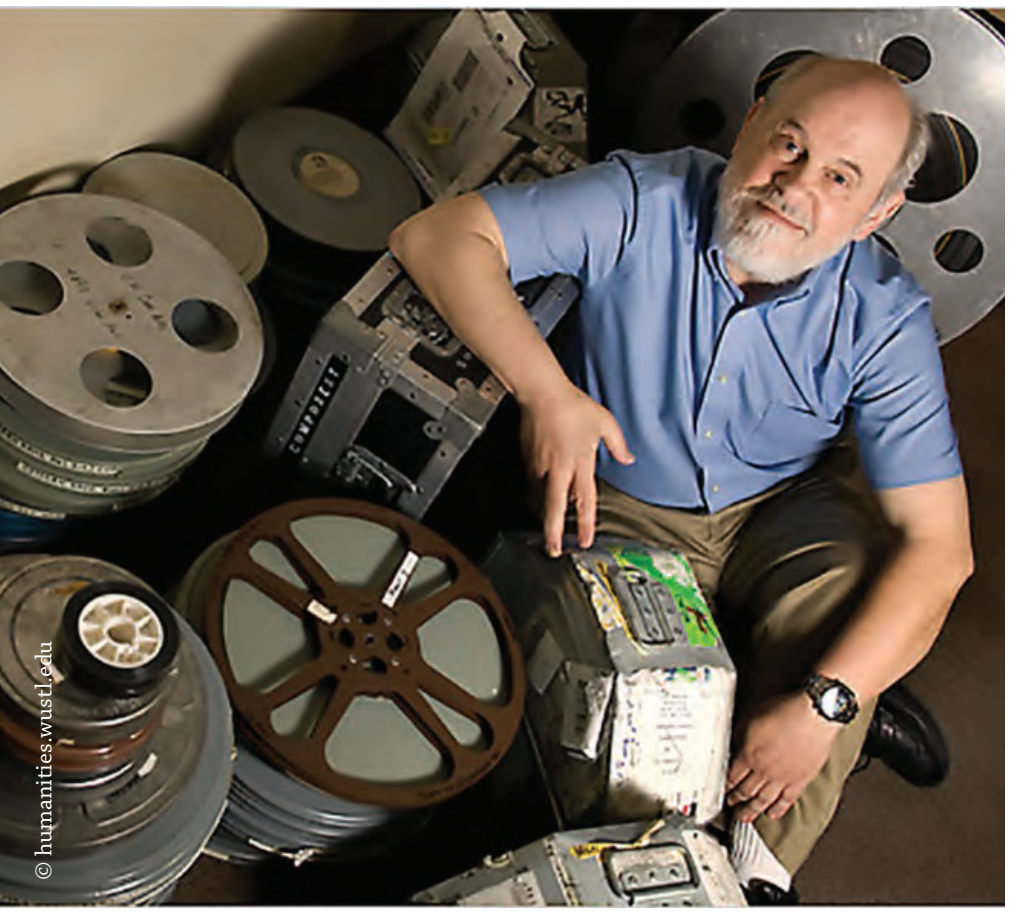

David Borbwell

Inspirado en los desarrollos de la psicología cognitiva, el teórico norteamericano David Bordwell planteó que la crítica de cine es un proceso de interpretación que relaciona actividades sociales, procesos de pensamiento, escritura y discurso, e instituciones y normas. Según esta formulación, la elaboración del significado fílmico es un proceso institucional altamente convencionalizado a través de rutinas y normas que llevan a la resolución de problemas cognitivos y retóricos.

Lejos de cualquier concepción romántica que explique el texto a través del mundo interior o el alma del crítico, la crítica debe concebirse, en la urdimbre del mundo y la escritura, como una práctica social que está sujeta a distintas regulaciones no solo institucionales y cognitivas, sino también epistemológicas, discursivas y políticas. El texto crítico, como el texto fílmico, es un enmarañado tejido hecho de hilos sociales, culturales, institucionales, políticos e ideológicos. El texto crítico y la película están embebidas en el mundo, sus tensiones, sus disputas. Por esta razón, un pensador tan agudo como Edward Said ha planteado la necesidad de entender el texto como un objeto mundano permanentemente contaminado por las circunstancias, los acontecimientos y las sensaciones que lo construyeron.

En síntesis, consideramos a la crítica como una escritura que crea sentidos que escapan a las verdades establecidas por el poder, a través de la afirmación de un punto de vista personal que toma partido dentro de la disputa pública por la interpretación. Independientemente de si la crítica se ejerce en el campo del periodismo, el ensayo literario o el texto académico, es un acto creativo que modifica, subvierte e inventa tanto a la obra como a la subjetividad del intérprete.

La crítica ha sido un oficio constante a lo largo de mi vida profesional, que se ha desarrollado en el ámbito cultural y académico. Sea a través de textos publicados en diarios, en revistas especializadas o en publicaciones académicas, siempre vuelvo al oficio de la crítica entendido como tarea de crear sentido desde un punto de vista personal y fundamentado sobre una obra concreta. Confieso que siempre me he sentido un anfibio que habita alternativamente las refrescantes aguas del cine y las sólidas tierras de las ciencias sociales. Durante mucho tiempo sentí que esos dos mundos eran incompatibles, tenían sus propios espacios, actores y lenguajes. Hasta que descubrí los estudios culturales -más tarde, los estudios visuales-, que permitían traficar perspectivas, lenguajes y conceptos de un campo hacia el otro y viceversa. Desde un inicio, la mirada anfibia me permitió 
ver con extrañeza el canon cinematográfico y los valores cinéfilos; asimismo, cuestionar la cine-fobia y el logocentrismo que caracterizaban el ambiente universitario.

Por esta razón, mi perspectiva crítica ha sido impura, profana y liminal. Apelando a las ideas de Edward Said, comentadas más arriba, practiqué la crítica como un ejercicio mundano contaminado por aspectos sociales, culturales y políticos. Nunca me sentí a gusto con cierto aire de sacralidad que los círculos de amantes del cine adjudicaban a determinados directores o películas. Concuerdo con Emmanuel Burdeau cuando cuestiona la «clausura cinéfila», esa actitud conservadora que se niega a incorporar nuevos lenguajes, formatos y tecnologías dentro del universo de lo que consideramos cine. $\mathrm{Mi}$ perspectiva crítica fue madurando contra este tipo de clausura, en busca de tornar legibles las profundas transformaciones que atraviesa el arte cinematográfico en los últimos años.

A fines del siglo XX, cuando empecé a escribir crítica, emergió una nueva generación de realizadores, programadores, investigadores y gestores cinematográficos que posicionaron una nueva manera de valorar el cine. La intelectualidad y las instituciones culturales dominantes durante los años 70 y 90 legitimaron el canon del cine clásico y moderno y abogaron por un cine ecuatoriano basado en el realismo social y el nacionalismo. Entrados los años 90 - por efectos de la crisis económica, el fin de utopías, las nuevas tecnologías y la globalización- apareció una nueva generación de actores en el campo cinematográfico alejada del realismo social y los ideales nacionalistas de los 80 .

En este contexto de renovación generacional, cuestionamiento de los valores heredados, crítica de la cultura elitista y tradición cineclubista, fue madurando mi perspectiva crítica. Visto a la distancia, creo poder explicar este posicionamiento a través de seis aspectos: la crítica de conceptos del cine clásico y moderno, la valoración de la cultura audiovisual, las nuevas formas de producción y consumo cinematográfico, una perspectiva crítica situada, el cuestionamiento del canon euroamericano, y la consolidación de los cines latinoamericano y ecuatoriano.
En primer lugar, el cine y la crítica de los años 90 plantean un cuestionamiento a conceptos de realismo y mímesis, desarrollados en el contexto del cine clásico; pero también otros como los de autor, autonomía cinematográfica y puesta en escena, desarrollados para explicar el cine moderno. Efectivamente, la cultura posmoderna, la estética del pastiche y la imagen intertextual propusieron un conjunto de cuestionamientos a los valores del clasicismo y el modernismo cinematográfico. En segundo lugar, se plantea una relativización del lenguaje del cine para reivindicar los lenguajes de la televisión, el video, la publicidad, el videoclip, los medios digitales y las redes sociales en el campo ampliado de la cultura audiovisual. El discurso visual y narrativo del cine deja de ser el modelo central para convivir con una pluralidad de lenguajes frente a los cuales la apropiación, la mezcla o la simulación es la respuesta. En tercer lugar, pasamos de la tecnología cinematográfica — basada en la grabación óptica y en la proyección- a las

\section{6 \\ El discurso visual y narrativo del cine deja de ser el modelo central para convivir con una pluralidad de lenguajes frente a los cuales la apropiación, la mezcla o la simulación es la respuesta.}

tecnologías de producción y consumo digitales, en el contexto de la cultura transmedia. Desde la revolucionaria producción de filmes con cámaras digitales en los smartphones hasta el consumo en una multiplicidad de pantallas, desarrollado en sistemas bajo demanda o en diálogo con la lógica de las redes sociales, asistimos a la mutación tecnológica más grande que haya tenido el cine desde sus orígenes.

Por otro lado, los años 90 son testigos de la consolidación de perspectivas críticas situadas desde el punto de vista cultural, político, geopolítico, de género y de sexualidad. Frente a la 
interpretación puramente formal o estética, la crítica contemporánea dialoga con el feminismo, la teoría queer, el poscolonialismo y los estudios de migraciones. Como lo ha planteado Robin Wood, poco a poco los críticos descubrimos y confesamos el posicionamiento de nuestra mirada, entendemos que nuestras notas se originan en una poderosa conexión entre teoría, práctica y vida personal. En mi caso, este descubrimiento va a venir de entenderme como un crítico que lee y escribe desde esta periferia de la periferia que es Ecuador.

En quinto lugar, y a tono con el punto anterior, existe una emergencia a nivel mundial de los cines periféricos de Asia, África y América Latina que cuestionan el canon euroamericano sobre el que se construyó la interpretación del cine clásico y moderno. Geografías cinematográficas relegadas por el colonialismo y eurocentrismo se visibilizan a nivel internacional. Autores como Takeshi Kitano, Wong Kar-wai, Tsai Ming-liang, Jia Zhang-ke, Abbas Kiarostami, Apitchapong Weerasethakul, Raya Martin y Semih Kaplanoğlu ingresan al canon de los grandes autores.

\section{6}

Desde los años 90

vivimos un proceso de consolidación y afirmación del cine latinoamericano que actualmente es reconocido como uno de los mejores del mundo.

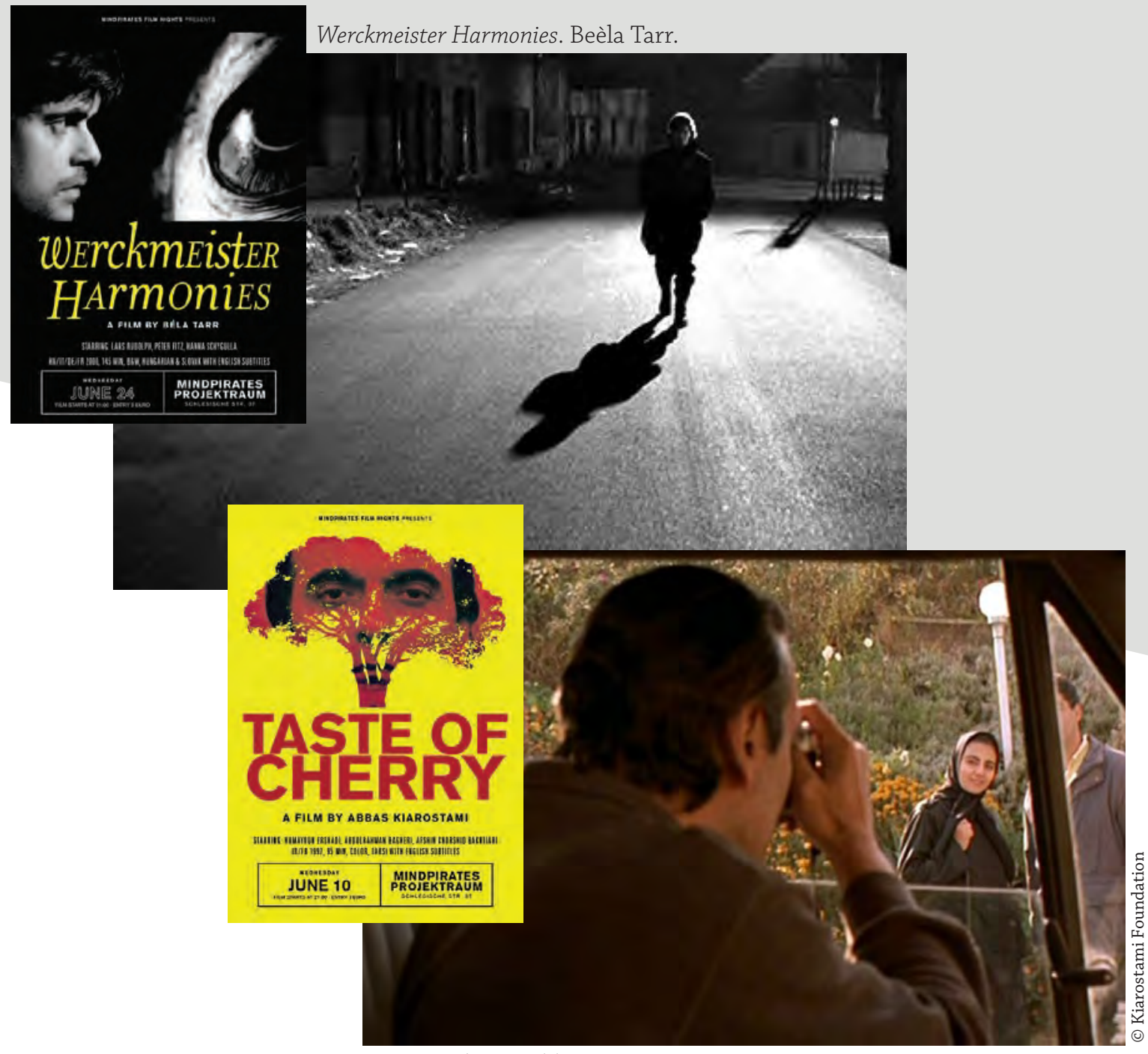


Finalmente —en la misma dirección-, desde los años 90 vivimos un proceso de consolidación y afirmación del cine latinoamericano que actualmente es reconocido como uno de los mejores del mundo. Carlos Reygadas, Alfonso Cuarón, Adrián Caetano, Lucrecia Martel, Ciro Guerra, Claudia Llosa y Fernando Meirelles son considerados directores imprescindibles en el cine contemporáneo. Al mismo tiempo, en Ecuador empezamos a vivir una consolidación del campo cinematográfico, que a partir del estreno de Ratas, ratones y rateros (1999) de Sebastián Cordero, y la Ley de Fomento al Cine Nacional (2006), afianza un proceso de profesionalización e institucionalización y permite una producción regular y sostenida como nunca antes existió.

Esta serie de desplazamientos de la mirada son un antecedente necesario para pensar los desafíos actuales del oficio crítico en una época caracterizada por el paro de la industria cinematográfica, la precipitación de la era postcinematográfica, el incremento del consumo audiovisual digital, el desconcierto generalizado y la crisis de sentido. Este tiempo, marcado por el coronavirus, la pandemia y el confinamiento, nos obliga a repensar el cine en su conjunto, nos exige volver a aquella virtud que consiste en cuestionar las certezas establecidas, imaginar los mundos por venir, a través de la interpretación y la construcción de uno mismo. Quizá hoy más que nunca el oficio de la crítica sea necesario para construir interpretaciones, entender el mundo, generar debate público y afirmar la subjetividad frente al desconcierto que signa los tiempos actuales.

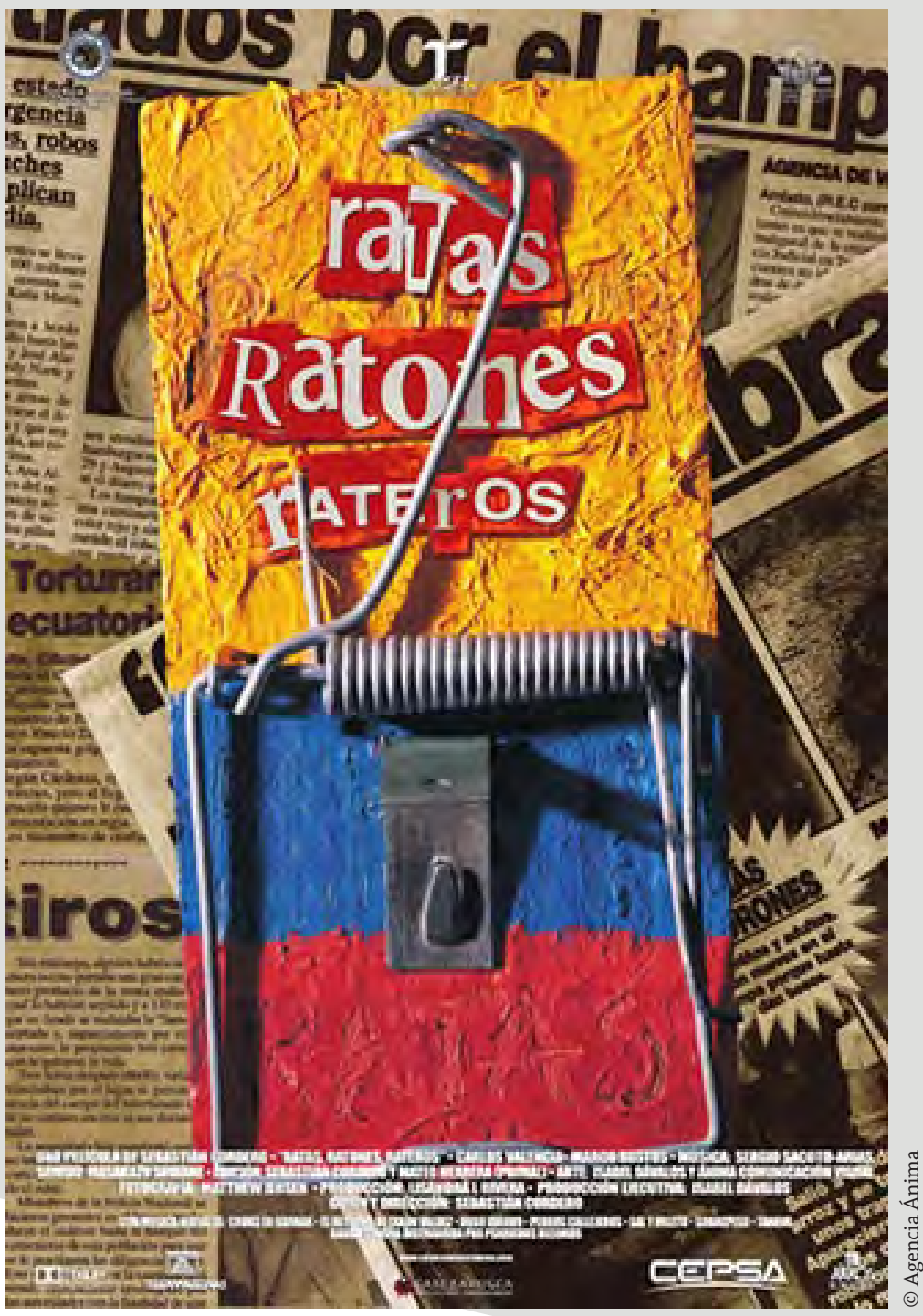

